\title{
離散双線形システムの可到達性
}

\author{
稲 垣 真 人*. 舟 橋 康 行*
}

\section{Reachability of Discrete Bilinear Systems}

\author{
Masato INAGAKI* and Yasuyuki FunAhAshi*
}

This paper considers the reachability of discrete bilinear systems described by

$$
\begin{array}{r}
x(t+1)=A x(t)+N x(t) u(t)+b u(t) \\
t=0,1,2, \cdots,
\end{array}
$$

where $u$ is scalar control. This problem has a solution when the control is bounded or rank $[N, b]=1$.

In this paper there is no such limitation on the control. First, the properties of the set of states reachable in $t$ steps from a nonzero initial state are investigated. Next, a sufficient condition for the existence of initial states, from which any state in $\boldsymbol{R}^{n}$ can be reached in $n$ steps, is presented. As a result the control sequence that transfers the initial state to any desired state can be obtained in an explicit way.

\section{1.はじめに}

現代システム制御理論は，状態空間法に基づいて展 開されており, 重要な基礎概念の一つに，いわゆる “可制御性” の概念がある. この “可制御性” は正確に は3 種類に分けられる。すすなわち，

（i）原点汇ある状態を，任意の状態仿移す有限長 の入力が存在するかどうかという可到達性（reachability),

（ii）任意の状態を, 原点に移す有限長の入力の存 在に関する可制御性 (controllability),

（iii） 任意の状態を，任意の状態に移す有限長の入 力が存在するかどうかという完全可制御性 (complete controllability),

なごの概念である. 定係数連続線形システムでは，乙 れらの概念はすべて等価である1?.しかし, ‘定係数離 散線形システムでは, 可到達性と完全可制御性とは等 価であるが，可制御性とは等価でない，つまり，シス テムが可到達（または, 完全可制御）なら可制御であ

* 名古屋大学工学部 名古屋市千種区不老町

* Faculty of Engineering, Nagoya University, Nagoya (Received August 22, 1977)
るのに対し，逆は一般に成立しない22.

こてで，双線形システムの “可制御性”、関する研 究をふり返ってみる. 連続双線形システムに対しては Rink ¿ $\mathrm{Mohler}^{3)}$ が, システムの平衡点の性質の研 究から，完全可制御の十分条件を与えている．実現問 題を解〈立場から, d'Alessandro ら ${ }^{4)}$ は原点加ら到達 可能な状態が生成する部分空間汇関する条件を得てい る.さらに, 微分幾何学の手法を用いる立場から, 数

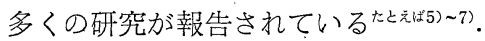

これに対して, 離散双線形システムの“可制御性” の研究は数少ない，Isidori ${ }^{87}$ は, 実現問題の立場から 原点からの可到達性の条件を与えた. しかし，一般に 可到達な状態の集合は線形空間とはならないので, 彼 の条件は，連続双線形システムに対する d'Alessandro らの条件と同様, 可到達な状態が生成する部分空間に 関するすのにすぎない，また，制御の立場からの研究 は, Tarn ら ${ }^{9}$, Goka ら ${ }^{10)}$, 山脇ら ${ }^{11}$ によるあのだけ である. このうち, Tarn らは，入力の大きさが微小 であるという制限のあとでの完全可制御の十分条件を 与えている，そのため，つぎの離散双線形システム

$$
x(t+1)=A x(t)+u(t) N x(t)+b u(t)
$$

に抢いて， ある $l<+\infty$ に対して $\left\|A^{2}\right\|=1$ が成立す るシステムに限られている. しかす, Heine-Borel の 被覆定理を用いて軌道を接続するという定性的な議 論をしているため, 実際の入力系列は得られない. Goka らむ, やはり完全可制御のための必要条件と十 分条件を与えているが, 考察しているシステムは, あ る限られたクラスに属するむのである.すなわち，上 記の方程式化いて, $\operatorname{rank}[N, b]=1$ の制約条件を 満たすシステムである. また, 山脇らも, 特別なクラ スのシステムに限定して議論している.

本研究では, 考察するシステムや, 入力の大きさに は上記のような制約をつけない時の可到達性を論じ る. 2 節では, 原点とは限らない初期状態から $t$ 時間 で到達可能な状態の集合の性質を調べる. 3 節では, システムの次元を $n$ とする時, $n$ 時刻目で到達可能な 
状態の集合が全空間となるような初期状態が存在する ための条件を与える，その結果，任意の終端状態に移 す大力系列を, 明確な形で求めることができる.

\section{2. 可到達性と可到達領域}

以下では，1 入力離散双線形システム BS を考え る.

$$
\text { BS : } \begin{gathered}
x(t+1)=A x(t)+u(t) N x(t)+b u(t) \\
t=0,1,2, \cdots
\end{gathered}
$$

ここで, $x(t) \in \boldsymbol{R}^{n}, u(t) \in \boldsymbol{R}$ で, $A, N, b$ はおのおの 適当なサイズの実行列である。 まず, 可到達性の定義 を与える.

【定義 2.1】 離散双線形システム BS において, 初 期状態 $x_{0}$ を, 状態 $x_{f}$ に移す有限長の入力系列 $\{u$ $(t)\} t=0,1, \cdots, L$ が存在する時, 状態 $x_{f}$ は $x_{0}$ か ら可到達であるという.

さて，以下の一連の記号を導入して (2.1) 式を書き かえる、すなわち、

$$
\begin{aligned}
& \left.\begin{array}{l}
x_{0}=x(0) \\
R_{1}\left(x_{0}\right)= \\
R_{i}\left(x_{0}\right)= \\
\quad N x_{0}+b \\
\quad N R^{i-1}\left(x_{0} x_{0}+b, A R_{i-1}\left(x_{0}\right),\right.
\end{array}\right\} \\
& U_{1}=u(0), \quad U_{i}=\left[\begin{array}{l}
u(i-1) \\
U_{i-1} \\
u(i-1) U_{i-1}
\end{array}\right] \quad i=2,3, \cdots
\end{aligned}
$$

とおくと，(2.1)式は

$$
x(t)=A^{t} x_{0}+R_{t}\left(x_{0}\right) U_{t}, t=1,2, \cdots
$$

と書くことができる，つぎに， $x_{0}$ から $t$ 時刻目で到 達可能なすべての状態の集合とその次元を定義する.

【定義 2.2】次式で与えられる集合を（ $x_{0}$ からの） $t$ 時刻可到達領域といい， $K\left(t, x_{0}\right)$ で表わす.

$$
\begin{aligned}
K\left(t, x_{0}\right)= & \left\{x(t) \in \boldsymbol{R}^{n} ; x(t)=A^{t} x_{0}+R_{t}\left(x_{0}\right) U_{t},\right. \\
& u(k) \in \boldsymbol{R}, 0 \leqq k \leqq t-1\}
\end{aligned}
$$

【定義 2.3】 $x_{0}$ 加らの可到達領域 $K\left(t, x_{0}\right)$ の次元 $\operatorname{dim} K\left(t, x_{0}\right)$ とは，乙の集合が生成する線形多様体 ${ }^{12)}$ $V(K)$ の次元を意味するすのとする.すなわち，

$$
\operatorname{dim} K\left(t, x_{0}\right)=\operatorname{dim} V(K)
$$

ただし

$$
\begin{gathered}
V(K)=\left\{x \in \boldsymbol{R}^{n} ; x=\alpha x_{1}+(1-\alpha) x_{2}, \alpha \in \boldsymbol{R},\right. \\
\left.x_{1}, x_{2} \in K\left(t, x_{0}\right)\right\}
\end{gathered}
$$

乙の時, $K\left(t, x_{0}\right)$ の次元数はつぎの定理で決定され る.

《定理 2.4》 ある固定された $x_{0}$ からの $t$ 時刻可到 達領域の次元数は, 行列 $R_{t}\left(x_{0}\right)$ の階数に等しい. す なわち,

$$
\operatorname{dim} K\left(t, x_{0}\right)=\operatorname{rank} R_{t}\left(x_{0}\right)
$$

(証明) $t$ 時刻可到達領域 $K\left(t, x_{0}\right)$ が生成する線 形多様体 $V(\dot{K})$ は，集合 $\left\{\bar{x} \in \boldsymbol{R}^{n} ; \bar{x}=R_{t}\left(x_{0}\right) U_{t}\right.$ 、 $u(k) \in \boldsymbol{R}, 0 \leqq k \leqq t-1\}$ が生成する部分空間を $A^{t} x_{0}$ だけ平行移動したものである。したがって，定理の証 明は，乙の部分空間の次元数が行列 $R_{t}\left(x_{0}\right)$ の階数に 等しいことを示すととである.

今，ある $x_{0}$ を固定した時, 行列 $R_{t}\left(x_{0}\right)$ の階数が $q$ であったとする. そこで, 行列 $R_{t}\left(x_{0}\right)$ から 1 次独 立な列ベクトル $r_{1}, \cdots, r_{q}$ 之，それに対応する係数 $d_{1}, \cdots, d_{q}$ を $U_{t}$ から取り出し，つぎの 1 次結合を考 える.

$$
h=d_{1} r_{1}+d_{2} r_{2}+\cdots+d_{q} r_{q}
$$
乙の時, 係数 $d_{1}, \cdots, d_{q}$ はお括のの, $\{u(0), u(1), \cdots$, $u(t-1)\}$ の変数の 1 個, 2 個の積, 3 個の積, $\cdots$ で 構成されている．また，乙の順序になっていると仮定 して一般性を失わない.すなわち

$$
\begin{aligned}
d_{i}=u\left(k_{1}\right) u\left(k_{2}\right) \cdots u\left(k_{l}\right), & 0 \leqq k_{1}<\cdots<k_{i} \leqq t-1 \\
& i=1,2, \cdots, q \quad(2.11)
\end{aligned}
$$

とおき, $d_{i}$ を定義する変数 $u(k)$ の個数を $\left|d_{i}\right|$ と書 くことにすると， $i<i^{\prime}$ ならば $\left|d_{i}\right| \leqq\left|d_{i^{\prime}}\right|$ である. さて， $d_{1}, \cdots, d_{q}$ はすべてが独立に值をとることは一 般にできない，しかし，(2.10)式の形の $q$ 本のベクト ル $h_{1}, \cdots h_{q}$ が 1 次独立となるように $u(k), k=0, \cdots$, $t$-1 の值を選ぶことができれば，てれら $q$ 本のベク トルが生成する部分空間の次元数は $q$ になる.すなわ ち,

$$
h_{j}=d_{1 j} r_{1}+d_{2_{j}} r_{2}+\cdots+d_{q j} r_{q}, \quad j=1,2, \cdots, q
$$

とおけば

$$
\left[\begin{array}{ll}
h_{1} & h_{2} \cdots h_{q}
\end{array}\right]=\left[\begin{array}{ll}
r_{1} & r_{2} \cdots r_{q}
\end{array}\right]\left[\begin{array}{ccc}
d_{11} & d_{12} \cdots d_{1 q} \\
d_{21} & d_{22} \cdots d_{2 q} \\
\vdots & \vdots & \vdots \\
d_{q 1} & d_{q 2} \cdots d_{q q}
\end{array}\right]
$$

となるから， $q \times q$ 行列 $D=\left[d_{i j}\right]$ が正則となるよう に $u(0), \cdots, u(t-1)$ の值を選べることを示せばよい. ここで明らかに, $d_{i 1}=\cdots=d_{i q}=d_{i}, i=1, \cdots, q$ であ る. $d_{j}=u\left(k_{1}\right) \cdots u\left(k_{l}\right)$ の時, $D$ の第 $j$ 列 $\left[d_{1 j}, \cdots\right.$, $\left.d_{q j}\right]^{T}$ の各要素には

$$
\left\{\begin{array}{l}
u\left(k_{1}\right)=\cdots=u\left(k_{l}\right)=1 \\
\text { 残りの } t-l \text { 個の } u(k)=0
\end{array}\right.
$$

とおいた時の $d_{1}, \cdots, d_{q}$ の值を上から順に代入する. この操作を $j$ にいて $1 \sim q$ まで繰り返す. $d_{1}, \cdots$, $d_{q}$ の並び方加 , 各 $j=1, \cdots, q$ について, $i<i^{\prime}$ な らば $\left|d_{i, j}\right| \leqq\left|d_{i^{\prime}, j}\right|$ であるので, $d_{i+1, j}, \cdots, d_{q, j}$ を 
定義する変数には, $u\left(k_{1}\right), \cdots, u\left(k_{l}\right)$ 以外の $u(k)$ が必 ず含まれる：したがって，

$$
\left\{\begin{array}{l}
d_{j, j}=1 \\
d_{j+1, j}=\cdots=d_{q, j}=0 \quad j=1,2, \cdots, q
\end{array}\right.
$$

となる，すなわち，行列 $D$ は, 対角要素がすべて 1 の 上三角行列となり，乙れは正則である．とのようにし て, ベクトル $h_{1}, \cdots, h_{q}$ は互いに 1 次独立であるよう にでき，てれらのベクトルが生成する部分空間の次元 数は $q$ となる.

(証明終)

(注意) 可到達性に関する Isidori らの結果 ${ }^{4), 8)}$ よれば， $n$ 次元双線形システムでは，有限時間内での (原点からの) 可到達領域が生成する部分空間は， $n$ 時 刻までの可到達領域が生成する部分空間に一致するこ とが示されている. これに対し, 定理 2.4 は, 各 $t$ 時刻ごとにその可到達領域 $K\left(t, x_{0}\right)$ の次元が行列 $R_{t}$ ( $\left.x_{0}\right)$ の階数に等しいことを主張するあのである.

一般に, 行列 $R_{t}\left(x_{0}\right)$ の階数は $x_{0}$ の值に依存する が，ある $x_{0}$ に対して最大階数 $q \leqq \min \left(n, 2^{t}-1\right)$ を むつ時, そうならない $x_{0}$ の集合は代数多様体 ${ }^{13)}$,14) を形成する，したがって， $R_{t}\left(x_{0}\right)$ の性質として，つ ぎのように述べることができる.

[命題 2.5] $t$ を固定した時, 行列 $R_{t}\left(x_{0}\right)$ の階数 を最大にする $x_{0} \in \boldsymbol{R}^{n}$ の集合は， $\boldsymbol{R}^{n}$ において開でか つ稠密である.

(注意) “開でかつ稠密”を“ほとんどすべて”と表 現するととむある14).

この命題の系として, $R_{t}\left(x_{0}\right)$ の階数が $n$ になるた めの一つの十分条件を与える.

[系 2.6] $n \leqq 2^{t}-1$ を満たす $t$ に対して, $R_{t}\left(x_{0}\right)$ をつぎのように分解する.

$$
R_{t}\left(x_{0}\right)=T_{t}\left(x_{0}\right)+P_{t}
$$

ただし， $P_{t}=R_{t}(0)$.

この時, $\operatorname{rank} P_{t}=n$ なら, ほとんどすべての $x_{0}$ に対して $\operatorname{rank} R_{t}\left(x_{0}\right)=n$ である.

(証明) 命題 2.5 から明らかである. (証明終)

(注意) $\operatorname{rank} P_{t}<n$ であってむ, $\operatorname{rank} R_{t}\left(x_{0}\right)=n$ がほとんどすべての $x_{0}$ についに成り立つ場合があ る.たとえば，

$$
\begin{aligned}
& A=\left[\begin{array}{ll}
1 & 0 \\
0 & 1
\end{array}\right], \quad N=\left[\begin{array}{ll}
0 & 1 \\
1 & 0
\end{array}\right], \quad b=\left[\begin{array}{l}
1 \\
1
\end{array}\right], \\
& x_{0}=\left[\begin{array}{l}
x_{0}^{1} \\
x_{0}{ }^{2}
\end{array}\right]
\end{aligned}
$$

という場合を考える。との時，

$$
\begin{aligned}
R_{2}\left(x_{0}\right) & =T_{2}\left(x_{0}\right)+P_{2} \\
& =\left[\begin{array}{lll}
x_{0}^{2} & x_{0}^{2} & x_{0}^{1} \\
x_{0}{ }^{1} & x_{0}{ }^{1} & x_{0}^{2}
\end{array}\right]+\left[\begin{array}{lll}
1 & 1 & 1 \\
1 & 1 & 1
\end{array}\right]
\end{aligned}
$$

となり, $\operatorname{rank} P_{2}=1<2$ であるが, $x_{0}^{2}-x_{0}{ }^{1} \neq 0$ およ び $x_{0}^{2}+x_{0}{ }^{1}+2 \neq 0$ なら $\operatorname{rank} R_{2}\left(x_{0}\right)=2$ である.

\section{3. $\boldsymbol{n}$ 時刻可到達領域 $\boldsymbol{K}\left(\boldsymbol{n}, \boldsymbol{x}_{0}\right)$}

線形システムと異なり，双線形システムでは，rank $R_{n}\left(x_{0}\right)=n$ であ可到達領域 $K\left(n, x_{0}\right)$ は一般に全空間 $\boldsymbol{R}^{n}$ とはならず，単に集合でしかない，乙れを例題で 見てみよう.

[例 1] つぎのような双線形システムを考える.

$$
\begin{gathered}
x(t+1)=\left[\begin{array}{ll}
0 & 0 \\
1 & 0
\end{array}\right] x(t)+\left[\begin{array}{ll}
1 & 0 \\
0 & 0
\end{array}\right] x(t) u(t) \\
+\left[\begin{array}{l}
1 \\
0
\end{array}\right] u(t) \\
x_{0}=\left[\begin{array}{l}
x_{0}^{1} \\
x_{0} 2
\end{array}\right]
\end{gathered}
$$

このシステムに対して, 行列 $R_{2}\left(x_{0}\right)$ を計算すると,

$$
R_{2}\left(x_{0}\right)=\left[\begin{array}{ccc}
1 & 0 & x_{0}^{1}+1 \\
0 & x_{0}^{1}+1 & 0
\end{array}\right]
$$

となり， $x_{0}{ }^{1} キ-1$ なら $\operatorname{rank} R_{2}\left(x_{0}\right)=2$ である. しか し, 可到達領域 $K\left(2, x_{0}\right)$ は，つぎのような集合に含 まれる.

$$
\begin{aligned}
K\left(2, x_{0}\right) & \subset\left\{(x, y) \in \boldsymbol{R}^{2} ; y \neq-1\right\} \\
\cup & \left\{(0,-1) \in \boldsymbol{R}^{2}\right\}, \quad \forall x_{0} \in \boldsymbol{R}^{2}
\end{aligned}
$$

[例 2]

$$
\begin{gathered}
x(t+1)=\left[\begin{array}{ll}
1 & 0 \\
0 & 0
\end{array}\right] x(t)+\left[\begin{array}{ll}
0 & 0 \\
1 & 0
\end{array}\right] x(t) u(t) \\
+\left[\begin{array}{l}
1 \\
0
\end{array}\right] u(t) \\
x_{0}=\left[\begin{array}{l}
x_{0}^{1} \\
x_{0}^{2}
\end{array}\right]
\end{gathered}
$$

という双線形システムにおいて, 行列 $R_{2}\left(x_{0}\right)$ は

$$
R_{2}\left(x_{0}\right)=\left[\begin{array}{ccc}
1 & 1 & 0 \\
x_{0} 1 & 0 & 1
\end{array}\right]
$$

である. したがって， $x_{0}$ がどのような值でも rank $R_{2}\left(x_{0}\right)=2$ となる. しかし, 可到達領域 $K\left(2, x_{0}\right)$ は, つぎの集合である.

$$
\begin{gathered}
K\left(2, x_{0}\right)=\left\{(x, y) \in \boldsymbol{R}^{2} ; y \leqq \frac{1}{4} x^{2}\right\}, \\
\forall x_{0} \in \boldsymbol{R}^{2}
\end{gathered}
$$

このように, $n$ 次元双線形システムにおいては, $n$ 時刻可到達領域 $K\left(n, x_{0}\right)$ は必ずしあ全空間 $\boldsymbol{R}^{n}$ とは ならない. 以下では，どのような場合に $K\left(n, x_{0}\right)$ が $\boldsymbol{R}^{n}$ と一致するかを考察する.

《定理 3.1》 $n \times\left(2^{n}-1\right)$ 行列 $R_{n}\left(x_{0}\right)$ を, $n \times n$ 行 列 $R_{n}{ }^{1}\left(x_{0}\right)$ 之 $n \times\left(2^{n}-1-n\right)$ 行列 $R_{n}{ }^{2}\left(x_{0}\right)$ とに分解 する.すなわち, 


$$
R_{n}\left(x_{0}\right)=[\overbrace{R_{n}^{1}\left(x_{0}\right)}^{n}, \overbrace{R_{n}^{2}\left(x_{0}\right)}^{2^{n}-1-n}]
$$

との時, つぎの二つの条件

(i) $R_{n}^{2}\left(x_{0}\right)=0$

(ii) $\operatorname{rank} R_{n}{ }^{1}\left(x_{0}\right)=n$

を同時に満たす $x_{0}$ が存在するなら，双線形システム $\mathrm{BS}$ の $n$ 時刻可到達領域 $K\left(n, x_{0}\right)$ は全空間 $\boldsymbol{R}^{n}$ と一 致する。

(証明) (2.5)式から， $n$ 時刻の状態 $x(n)$ は

$$
\begin{aligned}
x(n) & =A^{n} x_{0}+R_{n}\left(x_{0}\right) U_{n} \\
& =A^{n} x_{0}+\left[R_{n}{ }^{1}\left(x_{0}\right), R_{n}{ }^{2}\left(x_{0}\right)\right] U_{n}
\end{aligned}
$$

である. $U_{i}$ の定義 $(2.4)$ から， $U_{n}$ の最初の $n$ 成分 は, $u(n-1), \cdots, u(1), u(0)$ である.したがって，(3.2)，

(3.3)式を同時に満たす $x_{0}$ が存在する時，(3.4)式は

$$
x(n)=A^{n} x_{0}+R_{n}{ }^{1}\left(x_{0}\right) U_{n}{ }^{1}
$$
ただし，

$$
U_{n}^{1}=[u(n-1), \cdots, u(0)]
$$

となり， $K\left(n, x_{0}\right)$ は $\boldsymbol{R}^{n}$ と一致する.

(注意) $N=0$ の時, $x_{0}$ の值に関係なく $R_{n}{ }^{2}\left(x_{0}\right)=$ 0 であり, $R_{n}{ }^{1}\left(x_{0}\right)=\left[b, A b, \cdots, A^{n-1} b\right]$ となる.す なわち, 定理 3.1 は, 線形システムの可到達性の条 件となる。

つぎに, 定理 3.1 の二つの条件を満たす $x_{0}$ が存在 するための条件を求める。まず，条件( i )を考える. 行列 $R_{i}\left(x_{0}\right)$ の定義(2.3) から， $R_{n}{ }^{2}\left(x_{0}\right)$ の各列べク トルは，たとえば $A^{n-2} N^{2} x_{0}+A^{n-2} N b$ のように， $H_{j} x_{0}+h_{j}\left(j=1, \cdots, 2^{n}-1-n\right)$ という形をしている. ここで, $H_{j}$ は $n \times n$ 行列を， $h_{j}$ は $n$ 次元べクトル を表わす記号である．乙れらの列べクトルをつぎのよ うに並べかえる.

$$
\left[\begin{array}{l}
H_{1} \\
H_{2} \\
\vdots \\
H_{2^{n}-1-n}
\end{array}\right] x_{0}+\left[\begin{array}{l}
h_{1} \\
h_{2} \\
\vdots \\
h_{2^{n}-1-n}
\end{array}\right]
$$

このとき，明らかに

$$
\begin{aligned}
R_{n}{ }^{2}\left(x_{0}\right) & =\left[H_{1} x_{0}+h_{1}, \cdots, H_{2^{n}-1-n} x_{0}+h_{2^{n}-1-n}\right] \\
& =0
\end{aligned}
$$

之,

$$
\left[\begin{array}{l}
H_{1} \\
\vdots \\
\dot{H}_{2^{n}-1-n}
\end{array}\right] x_{0}+\left[\begin{array}{l}
h_{1} \\
\vdots \\
\vdots \\
h_{2 n-1-n}
\end{array}\right]=0
$$

とは等価である。したがって，(3.2)式を満たす $x_{0}$ が 存在するかどうかという問題は，(3.7)式を満たす $x_{0}$ が存在するかどうかという問題に帰着される．乙の問 題に対しては，つぎの補題が成立する.

[補題 3.2] $x_{0}$ に関するつぎの方程式

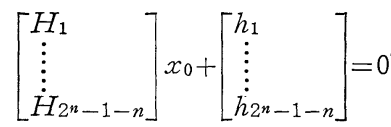

を満足する $x_{0} \in \boldsymbol{R}^{n}$ が存在するための必要十分条件 は,

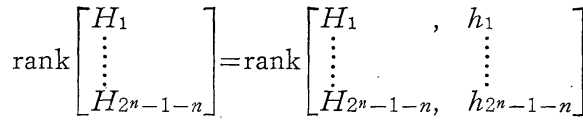

である，さらに，てのとき，xoはつぎのように表現 できる.

$$
x_{0}=-\boldsymbol{H}^{+} \boldsymbol{h}+\left(I_{n}-\boldsymbol{H}^{+} \boldsymbol{H}\right) \boldsymbol{z}
$$
ただし

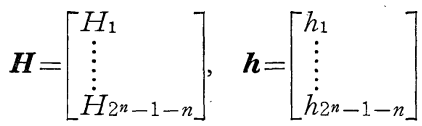

で, $\boldsymbol{H}^{+}$は $\boldsymbol{H}$ の擬似逆行列であり, $z$ は任意の $n$ 次 元ベクトルであでる.

この補題は，連立1次方程式に関するよく知られた 結果 ${ }^{15)}$ から直ちに証明できる。

今, $R_{n}{ }^{2}\left(x_{0}\right)=0$ が解をむつ時，その解は (3.9) 式の ように表わせた。 したがって，乙の $x_{0} を R_{n}^{1}\left(x_{0}\right)$ に 代入した時, その階数が $n$ となるような $n$ 次元べクト ル $z$ が存在すれば，その $x_{0}$ からの $n$ 時刻可到達領域 $K\left(n, x_{0}\right)$ は全空間 $\boldsymbol{R}^{n}$ と一致する，以上をまとめる と,つぎの定理を得る。

《定理 3.3》n次元双線形システム BS に扑てて,

(i.) $\operatorname{rank} \boldsymbol{H}=\operatorname{rank}[\boldsymbol{H}, \boldsymbol{h}]$ かつ

(ii) $\operatorname{rank} R_{n}{ }^{1}\left(-\boldsymbol{H}^{+} \boldsymbol{h}+\left(I_{n}-\boldsymbol{H}^{+} \boldsymbol{H}\right) z\right)=n(3.12)$ となる $n$ 次元べクトルが存在する時, (3.9)式を満た す $x_{0}$ に対して $n$ 時刻可到達領域 $K\left(n, x_{0}\right)$ は全空間 $\boldsymbol{R}^{n}$ と一致する．とこで， $\boldsymbol{H}$ と $\boldsymbol{h}$ は，(3.10)式で定 義した行列で, $\boldsymbol{H}^{+}$は $\boldsymbol{H}$ の擬似逆行列である.

$$
R_{n}^{2}\left(x_{0}\right)=0 \text { の解(3.9)の集合は， }
$$

$$
-\boldsymbol{H}^{+} \boldsymbol{h}+\mathrm{Null} \boldsymbol{H}
$$

とむ表わせる．乙の集合は，線形多様体であり， $V_{L}$ と書こう. また，命題 2.5 加, $\operatorname{rank} R_{n}{ }^{1}\left(x_{0}\right)=n$ と なる $x_{0}$ が存在すれば，そのような $x_{0}$ の集合は， $\boldsymbol{R}^{n}$ の中で開でかつ稠密である，逆にいえば， $R_{n}{ }^{1}\left(x_{0}\right)$ の階数を $n$ としない $x_{0}$ の集合は，代数多様体 $V_{A}$ を 形成する. この時, 定理 3.3 の二つの条件を幾何学的 に表現すると，つぎの系のように述べるとができ る。

[系 3.4] $n$ 次元双線形システム BS において, ぎの式で定義される集合が空集合でないとする。 


$$
X_{0}=V_{L}-\left(V_{L} \cap V_{A}\right)
$$

乙の時, $X_{0}$ に属する点 $x_{0}$ を初期状態とする $n$ 時 刻可到達領域 $K\left(n, x_{0}\right)$ は, 全空間 $\boldsymbol{R}^{n}$ と一致する. ここで, $V_{A}$ は， $R_{n}{ }^{1}\left(x_{0}\right)$ の階数を $n$ としない代数多 様体を表わす。

（証明）定理 3.3 の条件（i ）が成立するととと, $V_{L}$ が空集合でないことは等価である。ささらに，VA $R_{n}{ }^{1}\left(x_{0}\right)$ の階数を $n$ にしない $x_{0}$ の集合である. した がって，(3.14)式で定義される集合 $X_{0}$ が空でないな ら， $X_{0}$ の要素を初期状態とする $K\left(n, x_{0}\right)$ は $\boldsymbol{R}^{n}$ と 一致する.

(証明終)

また，初期状態 $x_{0}$ が集合 $X_{0}$ に属する時，任意の 終端状態へ移す入力系列は，つぎのようにして得られ る.

[系 3.5] 定理 3.3 の条件が満たされるとする. こ の時, (3.14)式で定義される集合 $X_{0}$ に属す初期状態 $x_{0}$ を, 任意の終端状態 $x_{f}$ へ移す入力系列は, 次式 で一意的に求まる.

$$
\left[\begin{array}{c}
u(n-1) \\
u(n-2) \\
\vdots \\
u(0)
\end{array}\right]=\left[R_{n}{ }^{1}\left(x_{0}\right)\right]^{-1}\left[x_{f}-A^{n} x_{0}\right], x_{0} \in X_{0}
$$

（証明）定理 3.3 の条件 (3.11)，(3.12)が満たされ る時, $x_{0} \in X_{0}$ に対しては, $R_{n}{ }^{2}\left(x_{0}\right)=0$ でかつ rank $R_{n}{ }^{1}\left(x_{0}\right)=n$ である. したがって, (3.5)，(3.6)式に おいて, $x(n)=x_{f}$ とおけば入力系列が求まる.

(証明終)

\section{4. 例 題}

次式で表わされる 1 入力離散双線形システムを考え る.

$$
\begin{aligned}
x(t+1)= & {\left[\begin{array}{ll}
2 & 2 \\
0 & 1
\end{array}\right] x(t)+\left[\begin{array}{rr}
1 & 0 \\
-1 & 0
\end{array}\right] x(t) u(t) } \\
& +\left[\begin{array}{r}
2 \\
-1
\end{array}\right] u(t) \\
x_{0}= & {\left[\begin{array}{l}
x_{0}^{1} \\
x_{0}{ }^{2}
\end{array}\right] }
\end{aligned}
$$

このシステムでは, 行列 $\boldsymbol{H}, \boldsymbol{h}$ はおのおの

$$
\boldsymbol{H}=N^{2}=\left[\begin{array}{rr}
1 & 0 \\
-1 & 0
\end{array}\right], \quad \boldsymbol{h}=N b=\left[\begin{array}{r}
2 \\
-2
\end{array}\right]
$$

であるから，定理 3.3 の条件 ( i ) が成立する，したが って $R_{2}^{2}\left(x_{0}\right)=0$ とする $x_{0}$ が存在する. 実際, $z=$ $\left[z^{1}, z^{2}\right]^{T}$ を任意のベクトルとすれば

$$
x_{0}=\left[-2, z^{2}\right]^{T} \text {. }
$$

で与えられる.

つぎに，条件( ii )，(3.12)式を調べる. (4.3)式で
記述される $x_{0}$ を $R_{2}{ }^{1}\left(x_{0}\right)$ に代入すると，

$$
\begin{aligned}
R_{2}{ }^{1}\left(x_{0}\right) & =\left[N A x_{0}+b, A N x_{0}+A b\right] \\
& =\left[\begin{array}{ll}
2 z^{2}-2 & 2 \\
3-2 z^{2} & 1
\end{array}\right]
\end{aligned}
$$

となる. 乙の時, $\operatorname{rank} R_{2}{ }^{1}\left(x_{0}\right)=2$ となる 2 次元べク トルは存在する．実際， $z^{2} \neq 4 / 3$ を満たす $z$ なら良い. このように，このシステムでは，2 時刻可到達領域 $K\left(2, x_{0}\right)$ が 2 次元平面 $\boldsymbol{R}^{2}$ と一致するような $x_{0}$ が存 在する.乙のような $x_{0}$ の集合を具体的に表わすと, つぎのようになる.

$$
X_{0}=\left\{\left[-2, \quad x_{0}^{2}\right]^{T} \in \boldsymbol{R}^{2} ; x_{0}^{2} \in \boldsymbol{R}, \quad x_{0}^{2} \neq \frac{4}{3}\right\}
$$

つぎに，集合 $X_{0}$ 上の点を，原点に移す入力系列を 求める. たとえば, $x_{0}=[-2,1]^{T}, x_{f}=[0,0]^{T}$ と する. (3.15)式から, 求める入力系列は

$$
\{u(0), u(1)\}=\{1 ;-2\}
$$

である.

\section{5. おわりに}

本稿では，1 入力離散双線形システムの可到達性を 考察した. まず, $t$ 時刻可到達領域 $K\left(t, x_{0}\right)$ の次元 が，入力の係数行列 $R_{t}\left(x_{0}\right)$ の階数等しいことを証 明し, つぎに, 行列 $R_{t}\left(x_{0}\right)$ の階数を最大にする $x_{0}$ は， $\boldsymbol{R}^{n}$ において開でかつ稠密な集合上にあることを 示した。 また, 線形システムとは異なり, 可到達領域 $K\left(t, x_{0}\right)$ は，一般に線形空間にならない。しかし，初 期状態 $x_{0}$ を限定すれば, $n$ 時刻可到達領域 $K\left(n, x_{0}\right)$ が，全空間 $\boldsymbol{R}^{n}$ と一致するととを示した，さらに， そのような $x_{0}$ が存在するための条件を与えた．その 結果, 任意の終端状態に移す入力系列を明確な形で表 わすととができた。

最後に, 日頃ご討論頂く中村嘉平教授に感謝します.

\section{参考文 献}

1) R. E. Kalman, P. L. Falb and M. A. Arbib: Topics in Mathematical System Theory, McGraw-Hill (1969)

2) 西村, 長田：線形離散システムの制御およで観湘につい て，システムと制御， 18-8，483/489 (1974)

3) R. E. Rink and R. R. Mohler: Completely Controllable Bilinear Systems, SIAM J. Control, 6-3, 477/ 486 (1968)

4) .P. d'Alessandro, A. Isidori and A. Ruberti : Realization and Structure Theory of Bilinear Dynamical Systems, SIAM J. Control, 12-2, 517/535 (1974)

5) R. W. Brockett : System Theory on Group Manifolds and Coset Spaces, SIAM J. Control, 10-2, 265/284 (1972)

6) H. J. Sussmann and V. Jurdjevic: Controllability 
of Nonlinear Systems, J. Differential Equations, 12, 95/116 (1972)

7) A. J. Krener: A Generalization of Chow's Theorem and Bang-Bang Theorem to Nonlinear Control Problems, SIAM J. Control, 12-1, 43/51 (1974)

8) A. Isidori: Direct Construction of Minimal Bilinear Realization from Nonlinear Input-Output Maps, IEEE Trans. on Automatic Control, AC-18-6, 626/ 631 (1973)

9) T.J. Tarn, D. L. Elliott and T. Goka: Controllability of Discrete Bilinear Systems with Bounded Control, IEEE Trans. on Automatic Control, AC18-3, 298/301 (1973)

10) T. Goka, T. J. Tarn and J. Zaborsky: On the
Controllability of a Class of Discrete Bilinear Systems, Automatica, 9, 615/622 (1973)

11）山脇, 馬場: 双線形離散システムの可制御, 第 15 回 SICE 学術講演会予稿集, 513/514 (1976)

12) D. G. Luenberger: Optimization by Vector Space Methods, John-Wiley \& Sons (1969)

13) W. M. Wonham: Linear Maltivariable Control; a Geometric Approach, Lecture Notes in Economics and Mathematical Systems, 101 (1974)

14) M. W. Hirsch and S. Smale: Differential Equations Dynamical Systems and Linear Algebra, Academic Press (1974)

15）览玉，須田：制御工学者のためのマトリクス理論 (26), システムと制御，17-10，621/629 (1973) 